\title{
Optimization of Fusion Zone Grain Size, Hardness, and Ultimate Tensile Strength of Pulsed Current Microplasma Arc Welded AISI 304L Sheets Using Genetic Algorithm
}

\author{
Siva Prasad Kondapalli, ${ }^{1}$ Srinivasa Rao Chalamalasetti, ${ }^{2}$ and Nageswara Rao Damera ${ }^{3}$ \\ ${ }^{1}$ Department of Mechanical Engineering, Anil Neerukonda Institute of Technology \& Sciences, Visakhapatnam 530 003, India \\ ${ }^{2}$ Department of Mechanical Engineering, AU College of Engineering, Andhra University, Visakhapatnam 531 162, India \\ ${ }^{3}$ Centurion University of Technology \& Management, Odisha 761 211, India \\ Correspondence should be addressed to Siva Prasad Kondapalli; kspanits@gmail.com
}

Received 18 September 2013; Accepted 28 January 2014; Published 5 March 2014

Academic Editor: Shia-Chung Chen

Copyright (c) 2014 Siva Prasad Kondapalli et al. This is an open access article distributed under the Creative Commons Attribution License, which permits unrestricted use, distribution, and reproduction in any medium, provided the original work is properly cited.

\begin{abstract}
Austenitic stainless steel sheets have gathered wide acceptance in the fabrication of components, which require high temperature resistance and corrosion resistance, such as metal bellows used in expansion joints in aircraft, aerospace, and petroleum industry. In case of single pass welding of thinner sections of this alloy, Pulsed Current Microplasma Arc Welding (PCMPAW) was found beneficial due to its advantages over the conventional continuous current process. The quality of welded joint depends on the grain size, hardness, and ultimate tensile strength, which have to be properly controlled and optimized to ensure better economy and desirable mechanical characteristics of the weld. This paper highlights the development of empirical mathematical equations using multiple regression analysis, correlating various process parameters to grain size, and ultimate tensile strength in PCMPAW of AISI 304L sheets. The experiments were conducted based on a five-factor, five-level central composite rotatable design matrix. A genetic algorithm (GA) was developed to optimize the process parameters for achieving the desired grain size, hardness, and ultimate tensile strength.
\end{abstract}

\section{Introduction}

AISI $304 \mathrm{~L}$ is an austenitic stainless steel with excellent strength and good ductility at high temperature. Typical applications include aeroengine hot section components, miscellaneous hardware, tooling, and liquid rocket components involving cryogenic temperature. AISI 304L can be joined using a variety of welding methods, including Gas Tungsten Arc Welding (GTAW), Plasma Arc Welding (PAW), Laser Beam Welding (LBW), and Electron Beam Welding (EBW). Of these methods, low current PAW (Micro-PAW) has attracted particular attention and has been used extensively for the fabrication of metal bellows, diaphragms which require high strength and toughness. PAW is conveniently carried out using one of two different current modes, namely, a continuous current (CC) mode or a pulsed current (PC) mode.
Pulsed current MPAW involves cycling the welding current at selected regular frequency. The maximum current is selected to give adequate penetration and bead contour, while the minimum is set at a level sufficient to maintain a stable arc $[1,2]$. This permits arc energy to be used effectively to fuse a spot of controlled dimensions in a short time producing the weld as a series of overlapping nuggets. By contrast, in constant to current welding, the heat required to melt the base material is supplied only during the peak current pulses allowing the heat to dissipate into the base material leading to narrower heat affected zone (HAZ). Advantages include improved bead contours, greater tolerance to heat sink variations, lower heat input requirements, reduced residual stresses and distortion, and refinement of fusion zone microstructure and reduced width of HAZ. There are four independent parameters that influence the process and they are peak current, back current, pulse, and pulse width. 
TABLE 1: Chemical composition of AISI 304L (weight\%).

\begin{tabular}{lccccccccc}
\hline C & $\mathrm{Si}$ & $\mathrm{Mn}$ & $\mathrm{P}$ & $\mathrm{S}$ & $\mathrm{Cr}$ & $\mathrm{Ni}$ & $\mathrm{Mo}$ & $\mathrm{Ti}$ & $\mathrm{N}$ \\
\hline 0.021 & 0.35 & 1.27 & 0.030 & 0.001 & 18.10 & 8.02 & - & - & 0.053 \\
\hline
\end{tabular}

In this investigation, experiments conducted using the design of experiments concept were used for developing mathematical models to predict such variables. Many works were reported in the past for predicting bead geometry, heat affected zone, bead volume, and so forth, using mathematical models for various welding processes [3-5]. Usually, the desired welding process parameters are determined based on the experience of skilled workers or from the data available in the handbook. This does not ensure the formation of optimal or near optimal weld pool geometry [6]. It has been proven by several researchers that efficient use of statistical design of experiment techniques and other optimization tools can impart scientific approach in welding procedure $[7,8]$. These techniques can be used to achieve optimal or near optimal bead geometry from the selected process parameters.

Kim et al. reviewed that optimization using regression modeling, neural network, and Taguchi methods could be effective only when the welding process was set near the optimal conditions or at a stable operating range [9], but nearoptimal conditions cannot be easily determined through full-factorial experiments when the number of experiments and levels of variables are increased. Also, the method of steepest ascent based upon derivatives can lead to an incorrect direction of search due to the nonlinear characteristics of the welding process. Genetic algorithm, being a global algorithm, can overcome the above problems associated with full-factorial experiments and the objective function to be optimized using GA need not be differentiable [10].

In the present study, a sequential genetic algorithm has been used to optimize the process parameters and achieve minimum fusion zone grain size, maximum hardness, and ultimate tensile strength of PCMPAW AISI 304L sheets.

\section{Experimental Procedure}

Austenitic stainless steel (AISI 304L) sheets of $100 \times 150 \times$ $0.25 \mathrm{~mm}$ are welded autogenously with square butt joint without edge preparation. The chemical composition of SS304L stainless steel sheet is given in Table 1. High purity argon gas (99.99\%) is used as a shielding gas and a trailing gas right after welding to prevent absorption of oxygen and nitrogen from the atmosphere. The welding has been carried out under the welding conditions presented in Table 2. From the literature four important factors of pulsed current MPAW as presented in Table 3 are chosen. A large number of trail experiments were carried out using $0.25 \mathrm{~mm}$ thick AISI 304L sheets to find out the feasible working limits of pulsed current MPAW process parameters. Due to a wide range of factors, it has been decided to use four-factor, five-level rotatable central composite design matrix to perform the number of experiments for investigation. Table 4 indicates the 31 set of coded conditions used to form the design matrix. The first sixteen experimental conditions (rows) have been formed for main
TABLE 2: Welding conditions.

\begin{tabular}{ll}
\hline & Secheron Microplasma Arc \\
Power source & Machine (Model: PLASMAFIX \\
Polarity & DCEN \\
Mode of operation & Pulse mode \\
Electrode & $2 \%$ thoriated tungsten electrode \\
Electrode diameter & $1 \mathrm{~mm}$ \\
Plasma gas & Argon and hydrogen \\
Plasma gas flow rate & $6 \mathrm{Lpm}$ \\
Shielding gas & Argon \\
Shielding gas flow rate & $0.4 \mathrm{Lpm}$ \\
Purging gas & Argon \\
Purging gas flow rate & $0.4 \mathrm{Lpm}$ \\
Copper nozzle diameter & $1 \mathrm{~mm}$ \\
Nozzle to plate distance & $1 \mathrm{~mm}$ \\
Welding speed & $260 \mathrm{~mm} / \mathrm{min}$ \\
Torch position & Vertical \\
Operation type & Automatic \\
\hline
\end{tabular}

effects. The next eight experimental conditions are called corner points and the last seven experimental conditions are known as center points. The method of designing such matrix is dealt elsewhere $[11,12]$. For the convenience of recording and processing the experimental data, the upper and lower levels of the factors are coded as +2 and -2 , respectively, and the coded values of any intermediate levels can be calculated by using the expression [13]

$$
X_{i}=\frac{2\left[2 X-\left(X_{\max }+X_{\min }\right)\right]}{\left(X_{\max }-X_{\min }\right)},
$$

where $X_{i}$ is the required coded value of a parameter $X$. The $X$ is any value of the parameter from $X_{\min }$ to $X_{\max }$, where $X_{\min }$ is the lower limit of the parameter and $X_{\max }$ is the upper limit of the parameter.

\section{Recording the Responses}

3.1. Measurement of Grain Size. Three metallurgical samples are cut from each joint, with the first sample being located at $25 \mathrm{~mm}$ behind the trailing edge of the crater at the end of the weld and mounted using Bakelite. Sample preparation and mounting are done as per ASTM E 3-1 standard. The samples are surface grounded using 120 grit size belt with the help of belt grinder and polished using grade 1/0 (245 mesh size), grade $2 / 0$ (425 mesh size), and grade $3 / 0$ (515 mesh size) sand paper. The specimens are further polished by using aluminum oxide initially and by utilizing diamond paste and velvet cloth 
TABLE 3: Important factors and their levels.

\begin{tabular}{lcccccc}
\hline & & & Levels & & & \\
Serial number & Input factor & Units & -2 & -1 & 0 & +1 \\
\hline 1 & Peak current & Amperes & 6 & 6.5 & 7.5 & 8 \\
2 & Back current & Amperes & 3 & 3.5 & 4 & 4.5 \\
3 & Pulse rate & Pulses/second & 20 & 30 & 40 & 50 \\
4 & Pulse width & $\%$ & 30 & 40 & 50 & 60 \\
\hline
\end{tabular}

TABLE 4: Design matrix and experimental results.

\begin{tabular}{|c|c|c|c|c|c|c|c|}
\hline $\begin{array}{l}\text { Serial } \\
\text { number }\end{array}$ & $\begin{array}{c}\text { Peak current } \\
\text { (Amperes) }\end{array}$ & $\begin{array}{c}\text { Back current } \\
\text { (Amperes) }\end{array}$ & $\begin{array}{c}\text { Pulse rate } \\
\text { (pulses/second) }\end{array}$ & $\begin{array}{c}\text { Pulse width } \\
\text { (\%) }\end{array}$ & $\begin{array}{l}\text { Grain size } \\
\text { (Microns) }\end{array}$ & $\begin{array}{l}\text { Hardness } \\
(\mathrm{VHN})\end{array}$ & $\begin{array}{c}\text { Ultimate tensile } \\
\text { strength (UTS) } \\
\text { (Mpa) }\end{array}$ \\
\hline 1 & -1 & -1 & -1 & -1 & 20.812 & 198 & 713 \\
\hline 2 & 1 & -1 & -1 & -1 & 30.226 & 190 & 705 \\
\hline 3 & -1 & 1 & -1 & -1 & 21.508 & 199 & 718 \\
\hline 4 & 1 & 1 & -1 & -1 & 27.536 & 193 & 706 \\
\hline 5 & -1 & -1 & 1 & -1 & 27.323 & 193 & 706 \\
\hline 6 & 1 & -1 & 1 & -1 & 25.206 & 195 & 710 \\
\hline 7 & -1 & 1 & 1 & -1 & 25.994 & 195 & 705 \\
\hline 8 & 1 & 1 & 1 & -1 & 23.491 & 197 & 706 \\
\hline 9 & -1 & -1 & -1 & 1 & 26.290 & 194 & 705 \\
\hline 10 & 1 & -1 & -1 & 1 & 29.835 & 190 & 700 \\
\hline 11 & -1 & 1 & -1 & 1 & 20.605 & 200 & 715 \\
\hline 12 & 1 & 1 & -1 & 1 & 27.764 & 193 & 708 \\
\hline 13 & -1 & -1 & 1 & 1 & 30.095 & 190 & 698 \\
\hline 14 & 1 & -1 & 1 & 1 & 26.109 & 194 & 706 \\
\hline 15 & -1 & 1 & 1 & 1 & 27.385 & 193 & 704 \\
\hline 16 & 1 & 1 & 1 & 1 & 25.013 & 195 & 710 \\
\hline 17 & -2 & 0 & 0 & 0 & 20.788 & 196 & 710 \\
\hline 18 & 2 & 0 & 0 & 0 & 25.830 & 195 & 706 \\
\hline 19 & 0 & -2 & 0 & 0 & 31.663 & 188 & 701 \\
\hline 20 & 0 & 2 & 0 & 0 & 27.263 & 193 & 708 \\
\hline 21 & 0 & 0 & -2 & 0 & 25.270 & 195 & 712 \\
\hline 22 & 0 & 0 & 2 & 0 & 26.030 & 194 & 705 \\
\hline 23 & 0 & 0 & 0 & -2 & 24.626 & 195 & 711 \\
\hline 24 & 0 & 0 & 0 & 2 & 26.626 & 194 & 705 \\
\hline 25 & 0 & 0 & 0 & 0 & 24.845 & 196 & 710 \\
\hline 26 & 0 & 0 & 0 & 0 & 24.845 & 196 & 710 \\
\hline 27 & 0 & 0 & 0 & 0 & 20.145 & 200 & 720 \\
\hline 28 & 0 & 0 & 0 & 0 & 24.845 & 195 & 710 \\
\hline 29 & 0 & 0 & 0 & 0 & 20.045 & 201 & 718 \\
\hline 30 & 0 & 0 & 0 & 0 & 24.845 & 195 & 710 \\
\hline 31 & 0 & 0 & 0 & 0 & 20.445 & 198 & 712 \\
\hline
\end{tabular}

in a polishing machine. The polished specimens are etched by using $10 \%$ Oxalic acid solution to reveal the microstructure as per ASTM E407. Micrographs are taken using metallurgical microscope (Make: Carl Zeiss, Model: Axiovert 40MAT) at 100x magnification. The micrographs of parent metal zone and weld fusion zone are shown in Figures 1 and 2.
Grain size of parent metal and weld joint is measured by using Scanning Electron Microscope (Make: INCA Penta FETx3, Model: 7573). Figures 3 and 4 indicate the measurement of grain size for parent metal zone and weld fusion zone. Average values of grain size are presented in Table 4 . From Figure 2, it is understood that the weldments consist 


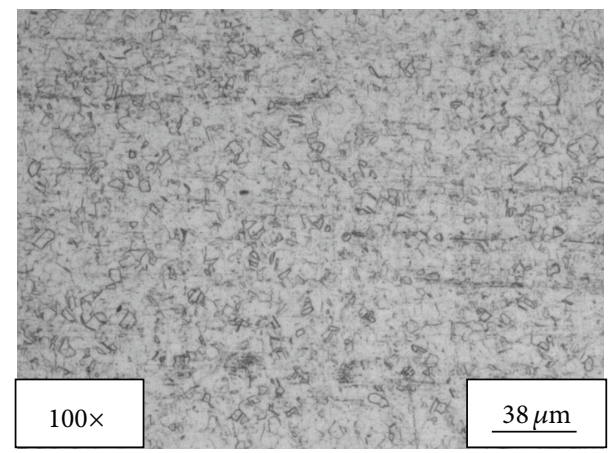

FIGURE 1: Microstructure of parent metal zone.

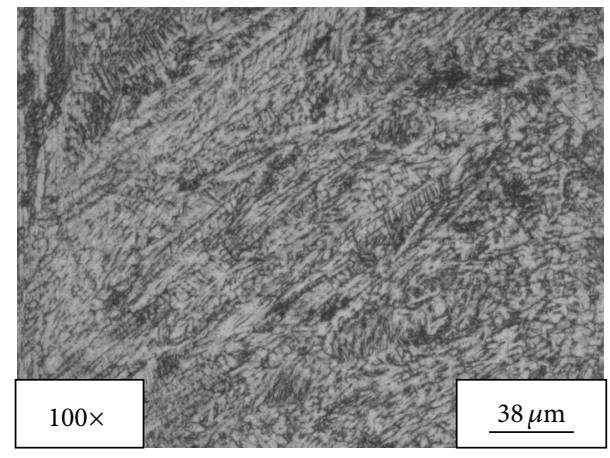

FIGURE 2: Microstructure of weld fusion zone.

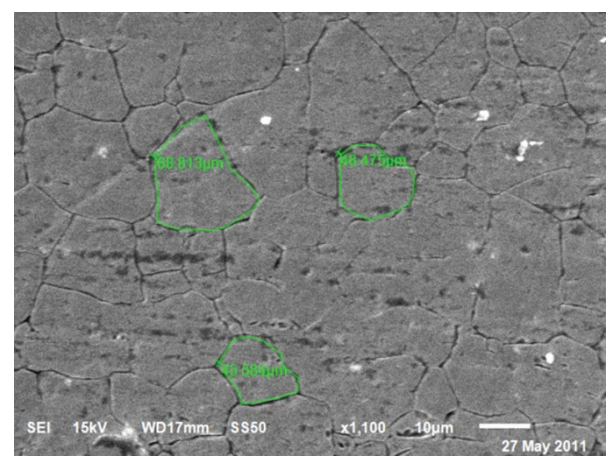

Figure 3: Grain size of parent metal.

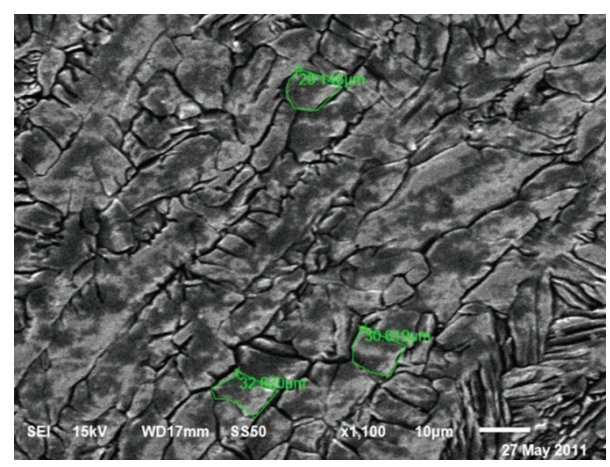

FIgURE 4: Grain size of weld fusion zone. of a columnar dendritic structure. A pronounced acicular $\delta$-ferrite formation (dark etching) is observed around the cellular dendritic austenitic grain.

3.2. Measurement of Hardness. Vickers's microhardness testing machine (Make: METSUZAWA CO., LTD, JAPAN, Model: MMT-X7) was used to measure the hardness at the weld fusion zone by applying a load of $0.5 \mathrm{Kg}$ as per ASTM E384. Average values of three samples of each test case are presented in Table 4.

3.3. Measurement of Ultimate Tensile Strength. Three transverse tensile specimens are prepared as per ASTM E8 M-04 guidelines and the specimens after wire cut Electro Discharge Machining are shown in Figure 2. Tensile tests are carried out in $100 \mathrm{KN}$ computer controlled Universal Testing Machine (ZENON, Model number: WDW-100) as shown in Figure 3. The specimen is loaded at a rate of $1.5 \mathrm{KN} / \mathrm{min}$ as per ASTM specifications, so that the tensile specimens undergo deformation. From the stress strain curve, the ultimate tensile strength of the weld joints is evaluated and the average of three results is presented in Table 4 .

\section{Developing Mathematical Models}

The output response of the weld joint $(Y)$ is a function of peak current $(A)$, back current $(B)$, pulse $(C)$, and pulse width $(D)$. It can be expressed as [14-16]

$$
Y=f(A, B, C, D) .
$$

The second order polynomial equation used to represent the response surface " $Y$ " is given by [11]

$$
Y=b_{o}+\sum b_{i} x_{i}+\sum \beta_{i i} x_{i}^{2}+\sum \sum b_{i j} x_{i} x_{j}+\varepsilon .
$$

Using MINITAB 14 statistical software package, the significant coefficients were determined and final model is developed using significant coefficients to estimate grain size, hardness, and ultimate tensile strength values of weld joint.

The final mathematical models are given by grain size $(G)$

$$
\begin{aligned}
G= & 22.859+1.052 X_{1}-1.058 X_{2} \\
& +0.315 X_{3}+0.625 X_{4}+1.640 X_{2}^{2}-2.320 X_{1} X_{3},
\end{aligned}
$$

hardness $(H)$

$$
\begin{aligned}
H= & 197.286-0.708 X_{1}+1.292 X_{2} \\
& -0.292 X_{3}-0.542 X_{4}-1.603 X_{2}^{2}+2.188 X_{1} X_{3},
\end{aligned}
$$

and ultimate tensile strength $(T)$

$$
\begin{aligned}
T= & 713.143-0.833 X_{1}+1.833 X_{2} \\
& -1.583 X_{3}-1.417 X_{4}-1.369 X_{1}^{2} \\
& -2.119 X_{2}^{2}+3.250 X_{1} X_{3}+1.750 X_{2} X_{4},
\end{aligned}
$$

where $X_{1}, X_{2}, X_{3}$, and $X_{4}$ are the coded values of peak current, back current, pulse rate, and pulse width. 
TABLE 5: ANOVA table.

\begin{tabular}{|c|c|c|c|c|c|c|}
\hline Source & $\mathrm{DF}$ & Seq SS & Adj SS & Adj MS & $F$ & $P$ \\
\hline \multicolumn{7}{|c|}{ Grain size } \\
\hline Regression & 14 & 249.023 & 249.023 & 17.7873 & 6.10 & 0.000 \\
\hline Linear & 4 & 65.207 & 65.207 & 16.3018 & 5.59 & 0.005 \\
\hline Square & 4 & 91.443 & 91.443 & 22.8608 & 7.84 & 0.001 \\
\hline Interaction & 6 & 92.372 & 92.372 & 15.3954 & 5.28 & 0.004 \\
\hline Residual error & 16 & 46.639 & 46.639 & 2.9149 & & \\
\hline Lack of fit & 10 & 9.750 & 9.750 & 0.9750 & 0.16 & 0.994 \\
\hline Pure error & 6 & 36.889 & 36.889 & 6.1481 & & \\
\hline Total & 30 & 295.661 & & & & \\
\hline \multicolumn{7}{|c|}{ Hardness } \\
\hline Regression & 14 & 228.18 & 228.18 & 16.299 & 5.67 & 0.001 \\
\hline Linear & 4 & 61.17 & 61.17 & 15.292 & 5.32 & 0.006 \\
\hline Square & 4 & 83.64 & 83.64 & 20.910 & 7.27 & 0.002 \\
\hline Interaction & 6 & 83.38 & 83.38 & 13.896 & 4.83 & 0.005 \\
\hline Residual error & 16 & 46.01 & 46.01 & 2.876 & & \\
\hline Lack of fit & 10 & 10.58 & 10.58 & 1.058 & 0.18 & 0.991 \\
\hline Pure Error & 6 & 35.43 & 35.43 & 5.905 & & \\
\hline Total & 30 & 274.19 & & & & \\
\hline \multicolumn{7}{|c|}{ Ultimate tensile strength } \\
\hline Regression & 14 & 676.218 & 676.218 & 48.3013 & 6.87 & 0.000 \\
\hline Linear & 4 & 205.667 & 205.667 & 51.4167 & 7.31 & 0.002 \\
\hline Square & 4 & 210.551 & 210.551 & 52.6379 & 7.48 & 0.001 \\
\hline Interaction & 6 & 260.000 & 260.000 & 43.3333 & 6.16 & 0.002 \\
\hline Residual error & 16 & 112.524 & 112.524 & 7.0327 & & \\
\hline Lack of fit & 10 & 1.667 & 1.667 & 0.1667 & 0.01 & 1.000 \\
\hline Pure error & 6 & 110.857 & 110.857 & 18.4762 & & \\
\hline Total & 30 & 788.742 & & & & \\
\hline
\end{tabular}

DF: degrees of freedom, SS: sum of squares, MS: mean squares, and $F$ : Fishers ratio.

\section{Checking the Adequacy of the Developed Models}

The adequacy of the developed models was tested using the analysis of variance technique (ANOVA). As per this technique, if the calculated value of the $F_{\text {ratio }}$ of the developed model is less than the standard $F_{\text {ratio }}$ (from $F$-table) value at a desired level of confidence (say 99\%), then the model is said to be adequate within the confidence limit. ANOVA test results are presented in Table 5 for all the models. From the table it is understood that the developed mathematical models are found to be adequate at $99 \%$ confidence level. The value of coefficient of determination " $R$ " for the above developed models is found to be about 0.85 .

From Table 5 it is understood that " $F$ " value for all the three output parameters are less than 7.87 (specified value in Fishers table for $99 \%$ confidence level). Hence we confirm the model is adequate at $99 \%$ confidence level.

\section{Optimization Procedure}

The purpose of optimization is to minimize grain size and maximize hardness and ultimate tensile strength. The tool used for optimization is GA. GA is an adaptive search and optimization algorithm that mimics principles of natural genetics. Due to their simplicity, ease of operation, minimum requirements, and global perspective they have been successfully used in a wide variety of problem domains [17].

6.1. Introduction to GA. GA simulates the survival of the fittest among individuals over consecutive generations for solving a problem. Each generation consists of a population of characters. Each individual represents a point in a search space and a possible solution. The individuals in the population are then made to go through a process of evolution. The basic concept of GA is to encode a potential solution to a problem as a series of parameters. A single set of parameter value is termed as the genome of an individual solution. An initial population of individuals is generated randomly. In every generation the individuals in the current population are decoded according to a fitness function. The chromosomes with the highest population fitness are selected for mating. The genes of the parameters are allowed to exchange to produce new ones. These new ones then replace the earlier ones in the next generation. Thus the old population is discarded and the new population becomes the current population. The 
TABLE 6: Parameters used in GA.

\begin{tabular}{lcccc}
\hline & & Grain size & Hardness & Ultimate tensile strength \\
\hline 1 & Sample size & 30 & 40 & 40 \\
2 & Crossover probability & 0.7 & 0.96 & 0.2 \\
3 & Mutation probability & 0.1 & 0.7 & 0.01 \\
4 & Number of generations & 100 & 100 & 100 \\
5 & Type of crossover & Single & Single & Single \\
\hline
\end{tabular}

current population is checked for acceptability or solution. The iteration is stopped after the completion of maximum number of generations or on the attainment of the best results [17-20]. below.

The GA algorithm for the optimization problem is given

Step 1: choose a coding to represent problem parameters, a selection operator, a crossover operator, and a mutation operator.

Step 2: choose population size $(n)$, crossover probability $(\mathrm{Pc})$, and mutation probability $(\mathrm{Pm})$.

Step 3: initialize a random population of strings of size $L$. Choose a maximum allowable generation number $G \max$. Set $G=0$. Evaluate each string in population.

Step 4: if $G>G \max$ or other termination criteria are satisfied, terminate or perform reproduction on the population.

Step 5: perform crossover on random pair of strings.

Step 6: perform mutation on every string.

Step 7: evaluate strings in the new population; set $G=$ $G+1$ and go to step 3 .

After applying the GA operators, a new set of population is created. Then they are decoded and objective function values are calculated. This completes one generation of GA. The number of generations is continued till the termination criterion is achieved. The parameters used in GA are presented in Table 6.

6.2. Objective Function. The optimization of grain size, hardness, and ultimate tensile strength was carried with the help of its mathematical equation. The mathematical equation is considered as objective function. The source code was developed using Turbo C. It is desirable to maximize hardness and ultimate tensile strength and minimize grain size. The objective function for minimizing grain size, as in (4), and maximizing hardness and ultimate tensile strength, as in (5) and (6), was taken as their fitness functions.

\subsection{Results of $G A$}

6.3.1. Grain Size. Figure 5 shows the results obtained by running the $C$ program. The initial variation in the curve is due to the search for optimum solution. It is evident that the minimum grain size of 22.13219 Microns is observed at the

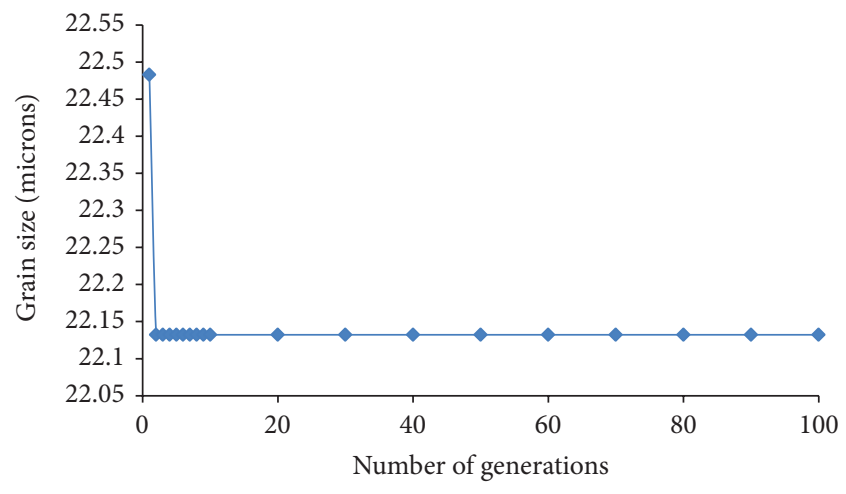

FIGURE 5: Variation of grain size with number of generations.

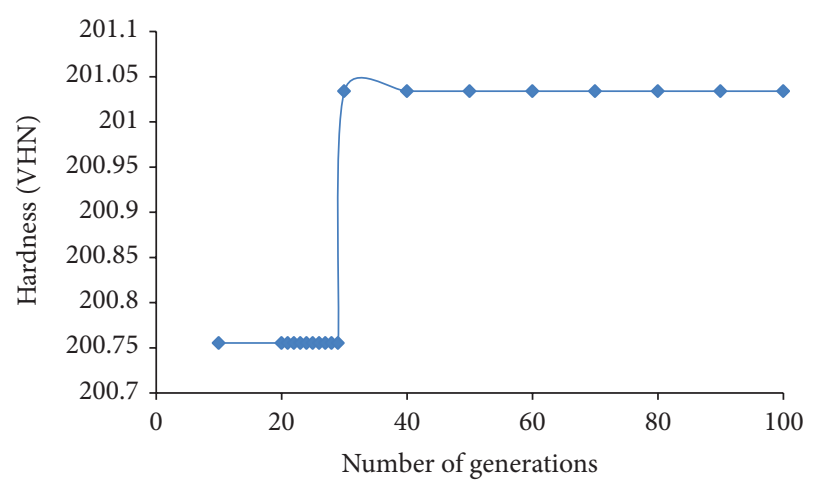

FIGURE 6: Variation of hardness with number of generations.

2nd iteration. It then converges to the same value up to 100 generations.

6.3.2. Hardness. Figure 6 shows the results obtained by running the $C$ program. The initial variation in the curve is due to the search for optimum solution. It is evident that the maximum hardness of 201.033981 VHN is observed at the 30 th iteration. It then converges to the same value up to 100 generations.

6.3.3. Ultimate Tensile Strength. Figure 7 shows the results obtained by running the $\mathrm{C}$ program. The initial variation in the curve is due to the search for optimum solution. It is evident that the maximum ultimate tensile strength of $718.7376 \mathrm{MPa}$ is observed at the 7 th iteration. It then converges to the same value up to 100 generations. 


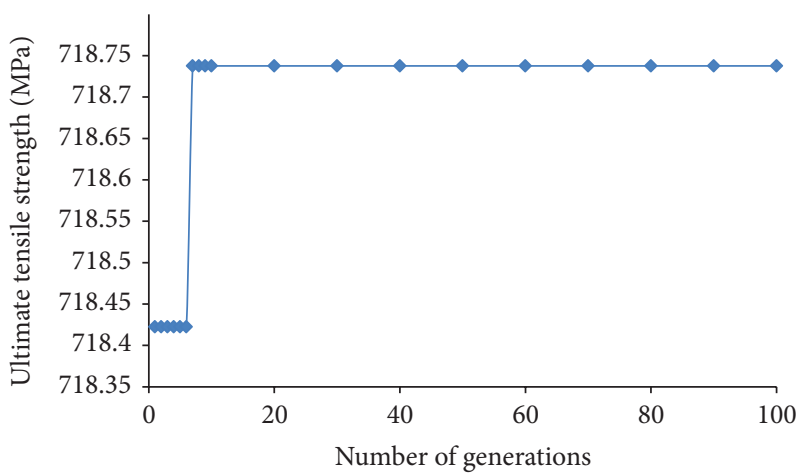

FIGURE 7: Variation of ultimate tensile strength with number of generations.

TABLE 7: Comparison of GA and experimental values.

\begin{tabular}{lcc}
\hline Welding parameters & $\begin{array}{c}\text { Experimental } \\
\text { values }\end{array}$ & GA values \\
\hline Peak current (Amperes) & Grain size & \\
Back current (Amperes) & 7 & 6.634 \\
Pulse rate (pulses/second) & 40 & 3.851 \\
Pulse width (\%) & 50 & 36.386 \\
Grain size (Microns) & Hardness & 55.011 \\
\hline & 7 & 22.13219 \\
Peak current (Amperes) & 4 & \\
Back current (Amperes) & 40 & 6.517 \\
Pulse rate (pulses/second) & 50 & 4.117 \\
Pulse width (\%) & 201 & 30.276 \\
Hardness (VHN) & Ultimate tensile strength & 40.4843 \\
& 7 & 201.033981 \\
Peak current (Amperes) & 4 & 6.514 \\
Back current (Amperes) & 40 & 3.912 \\
Pulse rate (pulses/second) & 50 & 30.098 \\
Pulse width (\%) & 720 & 40.004 \\
Ultimate tensile strength (Mpa) & & 718.7376 \\
\hline
\end{tabular}

\section{Results and Discussions}

Based on the results obtained in GA, the optimum values of PCMPAW input parameters and output responses like grain size, hardness, and ultimate tensile strength are computed and presented in Table 7 . The optimum grain size of 20.045 Microns is obtained for the welding input parameter combination of peak current 6.634 Amperes, back current 3.851 , pulse rate 36.383 pulses/second, and pulse width 55.011\%. The optimum hardness of 201.033981 VHN is obtained for the welding input parameter combination of peak current 6.517 Amperes, back current 4.117 Amperes, pulse rate 30.276 pulses/second, and pulse width 40.4842 . The optimum ultimate tensile strength of $718.7376 \mathrm{MPa}$ is obtained for the welding input parameter combination of peak current 6.514 Amperes, back current 3.912 Amperes, pulse rate 30.098 pulses/second, and pulse width $40.004 \%$. The optimum values obtained using genetic algorithm coincide with the experimental values

\section{Conclusions}

Empirical models are developed for grain size, hardness, and ultimate tensile strength for PCMPAW AISI 304L austenitic steel sheets using RSM CCD design matrix. The weld quality parameters like grain size, hardness, and ultimate tensile strength are optimized using GA. The objective is to minimize grain size and maximize hardness and ultimate tensile strength. The optimum values obtained using GA are 22.13219 Microns grain size, 201.033981 VHN hardness, and $718.7376 \mathrm{MPa}$ ultimate tensile strength. The optimum values obtained using GA are in good agreement with experimental values

\section{Conflict of Interests}

The authors declare that there is no conflict of interests regarding the publishing of this paper.

\section{Acknowledgments}

The authors would like to thank Shri. R. Gopla Krishnan, Director, M/s Metallic Bellows (I) Pvt Ltd, Chennai, India, and Mr. P. V. Vinay, Associate Professor, GVP College for PG courses (Technical Campus), Visakhapatnam, for their support to prepare this paper.

\section{References}

[1] M. Balasubramanian, V. Jayabalan, and V. Balasubramanian, "Effect of process parameters of pulsed current tungsten inert gas welding on weld pool geometry of titanium welds," Acta Metallurgica Sinica, vol. 23, no. 4, pp. 312-320, 2010.

[2] M. Balasubramanian, V. Jayabalan, and V. Balasubramanian, "Optimizing the pulsed current gas tungsten arc welding parameters," Journal of Materials Science and Technology, vol. 22 , no. 6, pp. 821-825, 2006.

[3] K. Marimuthu and N. Murugan, "Prediction and optimisation of weld bead geometry of plasma transferred arc hardfaced valve seat rings," Surface Engineering, vol. 19, no. 2, pp. 143-149, 2003.

[4] V. Gunaraj and N. Murugan, "Prediction and comparison of the area of the heat-affected zone for the bead-on-plate and beadon-joint in submerged arc welding of pipes," Journal of Materials Processing Technology, vol. 95, no. 1-3, pp. 246-261, 1999.

[5] V. Gunaraj and N. Murugan, "Application of response surface methodology for predicting weld bead quality in submerged arc welding of pipes," Journal of Materials Processing Technology, vol. 88, no. 1, pp. 266-275, 1999.

[6] S. C. Juang and Y. S. Tarng, "Process parameter selection for optimizing the weld pool geometry in the tungsten inert gas welding of stainless steel," Journal of Materials Processing Technology, vol. 122, no. 1, pp. 33-37, 2002.

[7] T. T. Allen, R. W. Richardson, D. P. Tagliabue, and G. P. Maul, "Statistical process design for robotic GMA welding of sheet metal," Welding Journal, vol. 81, no. 5, pp. 69s-172s, 2002. 
[8] I.-S. Kim, J.-S. San, and Y.-J. Jeung, "Control and optimization of bead width for mutipass-welding in robotic arc welding processes," Australian Welding Journal, vol. 46, pp. 43-46, 2001.

[9] D. Kim, M. Kang, and S. Rhee, "Determination of optimal welding conditions with a controlled random search procedure," Welding Journal, vol. 84, no. 8, pp. 125s-130s, 2005.

[10] D. Kim and S. Rhee, "Optimization of arc welding process parameters using a genetic algorithm," Welding Journal, vol. 80, no. 7, pp. 184s-189s, 2001.

[11] D. C. Montgomery, Design and Analysis of Experiments, John Wiley \& Sons, New York, NY, USA, 3rd edition, 1991.

[12] E. P. Boxg, W. H. Hunter, and J. S. Hunter, Statistics for Experiments, John Wiley \& Sons, New York, NY, USA, 1978.

[13] S. Babu, T. S. Kumar, and V. Balasubramanian, "Optimizing pulsed current gas tungsten arc welding parameters of AA6061 aluminium alloy using Hooke and Jeeves algorithm," Transactions of Nonferrous Metals Society of China, vol. 18, no. 5, pp. 1028-1036, 2008.

[14] W. G. Cochran and G. M. Cox, Experimental Designs, John Wiley \& Sons, London, UK, 1957.

[15] T. B. Barker, Quality by Experimental Design, Marcel Dekker, ASQ Quality Press, 1985.

[16] W. P. Gardiner and G. Gettinby, Experimental Design Techniques in Statistical Practice, Horwood, Chichester, UK, 1998.

[17] P. Palanisamy, I. Rajendran, and S. Shanmugasundaram, "Optimization of machining parameters using genetic algorithm and experimental validation for end-milling operations," International Journal of Advanced Manufacturing Technology, vol. 32, no. 7-8, pp. 644-655, 2007.

[18] N. Baskar, P. Asokan, G. Prabhaharan, and R. Saravanan, "Optimization of machining parameters for milling operations using non-conventional methods," The International Journal of Advanced Manufacturing Technology, vol. 25, no. 11-12, pp. 10781088, 2005.

[19] K. S. Prasad, C. S. Rao, and D. N. Rao, "Multi objective optimization of weld bead geometry parameters of pulsed current micro plasma arc welded inconel 625 sheets using enhanced non-dominated sorting genetic algorithm," Journal of Materials \& Metallurgical Engineering, vol. 3, no. 1, pp. 231-3818, 2013.

[20] K. S. Prasad, C. S. Rao, and D. N. Rao, "Optimization of pulsed current parameters to minimize pitting corrosion in pulsed current micro plasma arc welded AISI 304L sheets using genetic algorithm," International Journal of Lean Thinking, vol. 4, no. 1, pp. 9-19, 2013. 

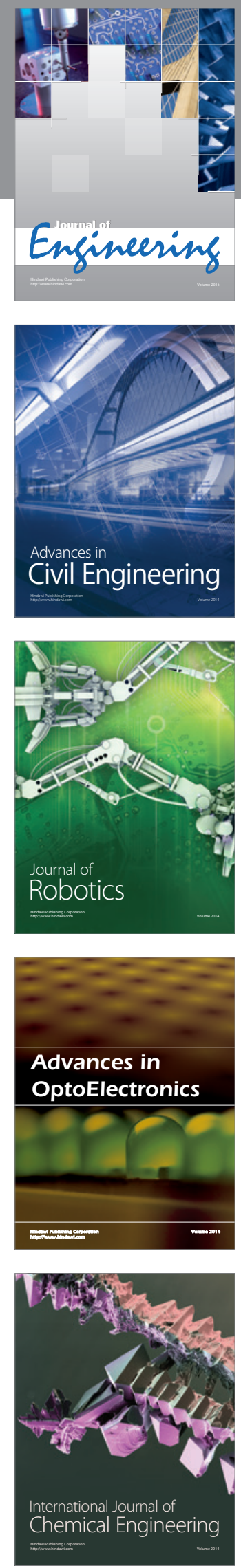

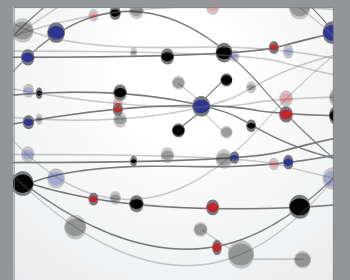

The Scientific World Journal
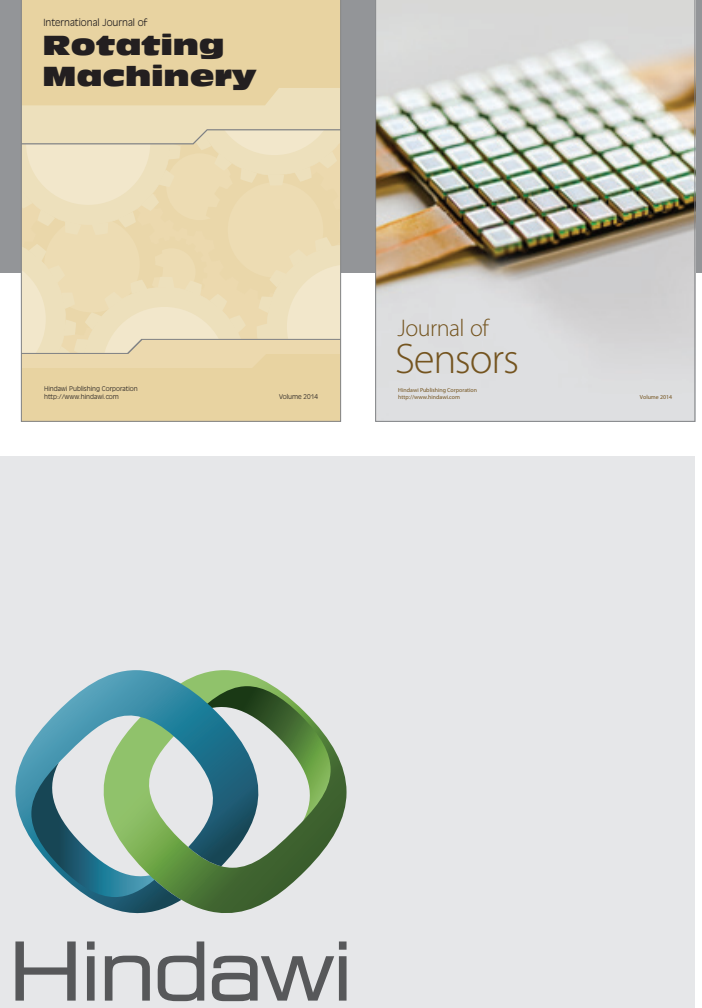

Submit your manuscripts at http://www.hindawi.com
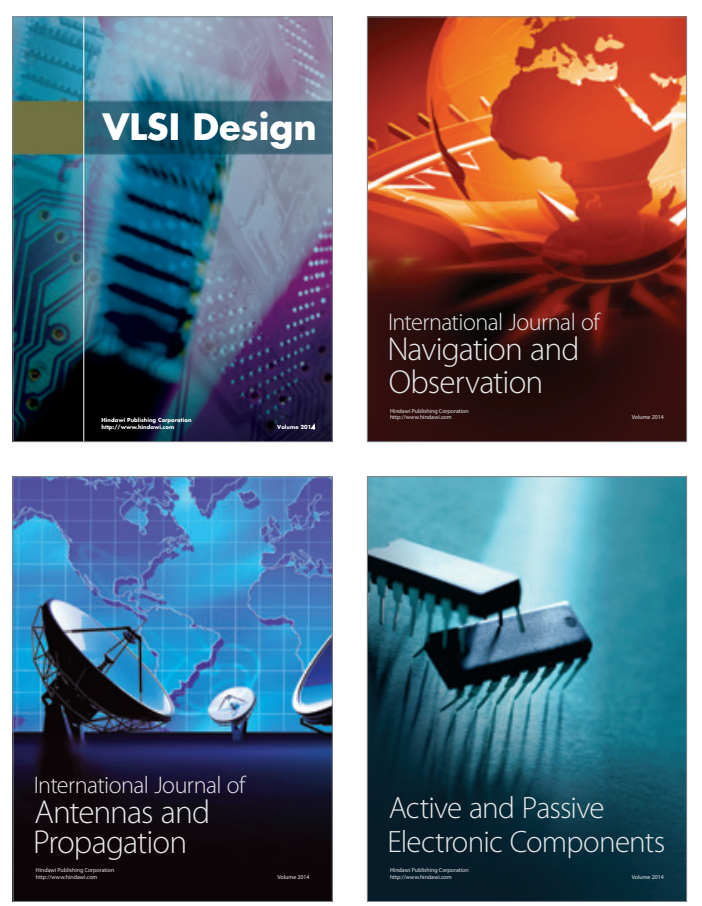
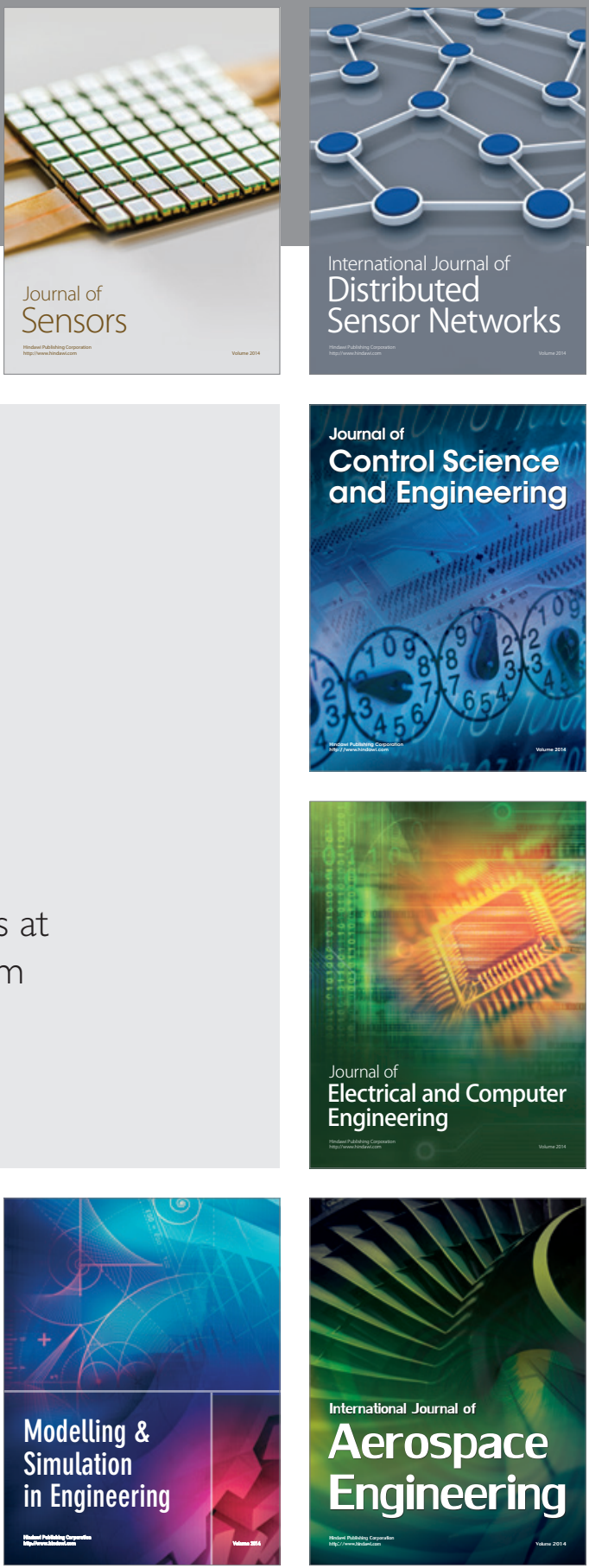

Journal of

Control Science

and Engineering
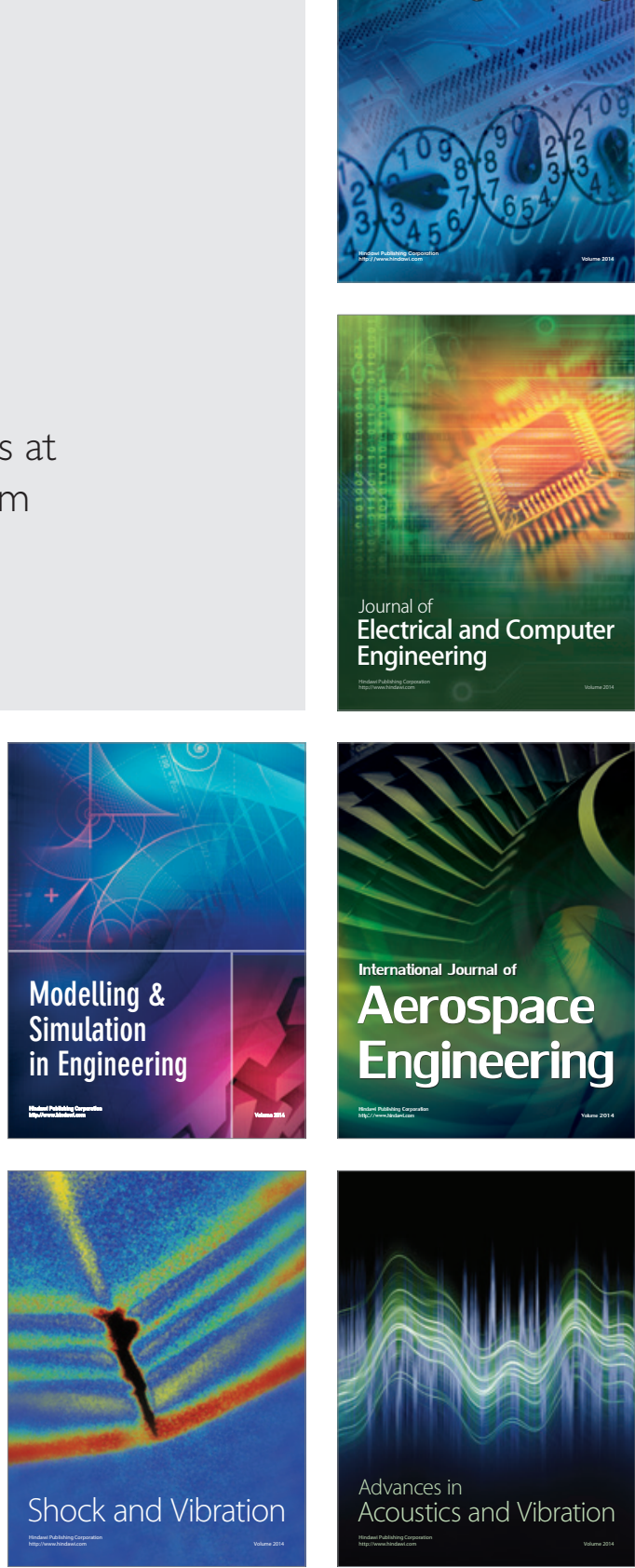